\title{
Observing Mathematics Teaching Practices to Promote Professional Development: An Analysis of Approaches to Probability
}

\author{
Claudia Vásquez ${ }^{1 *}$, Ángel Alsina ${ }^{2}$ \\ ${ }^{1}$ Pontificia Universidad Católica de Chile, CHILE \\ ${ }^{2}$ Universidad de Girona, SPAIN \\ *CORRESPONDENCE: $\gg$ cavasque@uc.cl
}

\begin{abstract}
This study aims to analyse the approaches to probability that were carried out by the participants of the teaching practice of Primary Education teachers and, more specifically, their teaching trajectories. To do this we analysed 23 video-recorded classes of all levels, using a previously validated instrument. Results show trajectories characterised by a strong presence of intuitive approach at initial levels, in conjunction with a much lower presence of frequency approach and an absence of other approaches. As the level increases, the presence of intuitive approach decreases, being replaced by subjective, frequency and classical ones, with the latter two having the greatest presence in the upper levels. We conclude that results will be useful for strengthening the professional development of Primary Education teachers in relation to the teaching of probability.
\end{abstract}

Keywords: teaching probability, approaches to probability, teaching trajectories, professional development, primary education

\section{INTRODUCTION}

Over recent years, the scientific community has agreed that citizens need to be statistically and probabilistically literate. In view of this, the study of statistics and probability has been included in Primary Education curricula in numerous countries (e.g. CCSSI, 2010; MEC, 2007; MINEDUC, 2012; Ministry of Education Singapore, 2007; National Curriculum, 1999; NCTM, 2000). This content has been included to promote students' capacity to interpret, critically assess and, when applicable, to express opinions on statistical information and arguments related to the data or stochastic phenomena. The aim is also for young students to gradually learn to access, use, interpret and communicate ideas and information related to chance and probability, in order to effectively manage situations that involve uncertainty and risk in the real world (Gal, 2005).

This article focuses on the teaching of probability given its utility and applicability in different fields of knowledge. On the one hand, we assume that its learning constitutes a baseline for understanding and studying more advanced subject-matter, by providing probabilistic models to measure the uncertainty that underpins part of statistical theory. On the other hand, learning probability helps develop critical thinking which in turn helps citizens understand and communicate information related to different phenomena of daily life (Everitt, 2008). As a result of this, it becomes necessary to educate students in this task from an early age in order to guarantee that citizens are probabilistically literate and "capable of dealing with a wide range of

Article History: Received 4 July $2019 \bullet$ Revised 25 July $2019 \bullet$ Accepted 26 July 2019

(C) 2019 by the authors; licensee Modestum Ltd., UK. Open Access terms of the Creative Commons Attribution 4.0 International License (http://creativecommons.org/licenses/by/4.0/) apply. The license permits unrestricted use, distribution, and reproduction in any medium, on the condition that users give exact credit to the original author(s) and the source, provide a link to the Creative Commons license, and indicate if they made any changes. 
real life situations that involve interpreting or generating probabilistic messages, as well as taking decisions" (Gal, 2005, p. 40).

Previous studies have highlighted the fact that the teaching of this knowledge in Primary Education is deficient (Vásquez \& Alsina, 2017, 2015). In view of this, our study aims to explore how this knowledge is taught. Our specific research questions are: How is probability taught in Primary Education classrooms? Are the different approaches linked to their interpretations introduced in the context of school mathematics? What does the teaching trajectory of these approaches comprise and what should it comprise? This final question is underpinned by the belief that a real understanding of probability is only possible if the student reflects on its nature, which is complex in the case of probability, despite being a relatively new branch of mathematics (Shaughnessy, 1992).

Within the framework of probability teaching, this article assumes that consideration should be given to the different approaches linked to interpretations of probability: intuitive, classical, frequency, subjective and axiomatic (Batanero, 2005). These interpretations, which were initially proposed for Secondary Education, underlie the different stages of the historical-epistemological development of probability:

\begin{abstract}
“approaches that should be introduced gradually, starting from students' intuitive ideas about chance and probability, since comprehension is a continuous and incremental process through which the student progressively constructs and relates the different elements of the meanings related to the concept" (Batanero, 2005, p. 257).
\end{abstract}

This study aims to analyse the approaches to probability that were carried out by the participants of the teaching practice of Primary Education teachers and, more specifically, their teaching trajectories. While it is true that we could carry out a documentary analysis of official curricula or even of the textbooks used in the classroom to know when certain content is introduced, we have opted to focus our analysis on teacher practice for two basic reasons: 1) since the official curriculum does not always coincide with the real curriculum, which in the specialised literature tends to be referred to as the hidden curriculum (Alsubaie, 2015; Orón \& Blasco, 2018); 2) since textbooks do not guarantee the effective teaching of probability in Primary Education, even more so in the case of probability, according to previous studies which have detected considerable deficits (Vásquez \& Alsina, 2015). Consequently, in order to carry out our study, we analysed 23 video-recorded classes on probability which covered the different levels of Primary Education (1st to 8th grade) of 12 Chilean teachers, with a view to taking subsequent decisions to contribute towards improving their professional practice.

\title{
TEACHING PROBABILITY AND APPROACHES TO IT IN PRIMARY EDUCATION
}

As indicated above, probability has been gradually introduced into the mathematics curricula of Primary Education (approximately 6 to 12 years old) in numerous countries. An in-depth review of the curricula of the different countries that have incorporated this content is beyond the scope of this current study (see Vásquez \& Alsina, 2014, for a review). The contributions made by the NCTM (2000) are analysed due to their international impact and influence on mathematics curricula. This organisation proposes that teaching programmes at all stages of education should help students "develop and assess inferences and predictions based on data and to understand and apply basic concepts of probability" (NCTM, 2000, p. 51). On the one hand, in relation to the development and assessment of inferences based on data, the indications state that students at initial stages should start to discuss probable and improbable events related to their own experiences, and that as their level increases they should acquire the skills needed to: a) use observations related to differences between two or more samples to formulate conjectures (on the populations from which they have been extracted and on the possible relations between two characteristics of a sample, on the basis of point clouds of the data and approximate line balancing); and b) use these conjectures to formulate new questions and to programme new studies to be addressed.

On the other hand, regarding the comprehension and application of basic concepts of probability, it is suggested that students at initial and intermediate levels should learn to describe events as probable or not probable, and to discuss degrees of probability using expressions such as certain, equally probable and improbable; to predict the probability of results of simple experiments and to test out said predictions; and to understand that the measurement of the probability of an event can be represented by a number between 0 and 1. At upper levels, and continuing in the following educational stage, students should start to understand and use the appropriate terminology to describe complementary and mutually exclusive events; use 


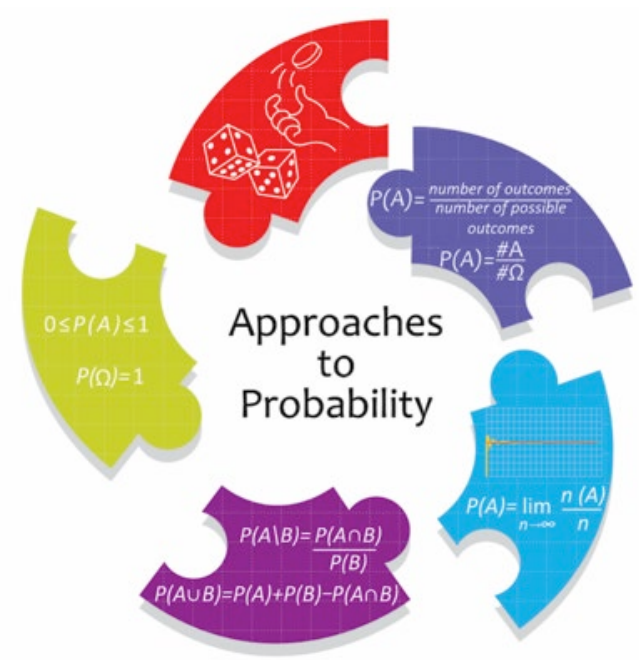

Figure 1. Approaches to probability in the context of school mathematics

proportionality, and have a basic understanding of probability to formulate and verify conjectures on the results of experiments and simulations; and also to calculate probabilities of easy compound events, using methods such as organised lists, tree diagrams and area models. In summary, for the NCTM (2000), the teaching of basic concepts of probability during Primary Education passes through different phases: a) it starts informally at initial stages, introducing the vocabulary related to notions of probability through activities focusing on comments made by students based on their own experiences; b) this is followed by the quantification of the possibility of an event occurring, thus introducing the interpretation of probability as a measurement; and c) it is completed with the calculation of probabilities of easy compound events, leaving the calculation of probability of dependent and independent events for the next stage, as well as more complex concepts.

The teaching of this knowledge should be aware of the different approaches to probability. If not, it is difficult to understand the obstacles and difficulties facing students who "will find the same paradoxes and counter-intuitive situations that appeared in the historical development of the calculation of probabilities" (Batanero, 2005, p. 28) during their own learning and construction process. These approaches, which are shown in Figure 1 in relation to stochastic experiments with dice and coins and the axiomatic experiments proposed by Kolmogorov, "implicitly determine students' behaviour and responses when faced with situations of chance in which they have to put into practice their intuition and probabilistic knowledge" (Batanero, Henry, \& Parzysz, 2005, p. 20), and which should therefore be taken into account when teaching this subject.

Intuitive approach: based on a qualitative assignation of probabilities. This conception appears in both children and adults who have not received training in probability and therefore rely on intuitive ideas (Batanero, 2005). Different terms from common language are used (possible, foreseeable, presumable, etc.), which already have previous meanings to refer to uncertainty and to express degrees of belief in relation to uncertain events. In line with Fischbein (1975), efforts are needed to literacise these initial intuitions from early ages, since experiences with chance can sometimes lead to the development of incorrect or imprecise intuitions related to chance and probability. Daily life contexts, and the use of games linked to chance and language associated with uncertainty can be useful for initiating studies of probability on the basis of students' intuitive ideas about chance.

Classical approach: this conception, which is also known as the Laplacian approach, is the first definition to formalise the classical approach to probability, which was published by de Moivre in Doctrine of Chance (de Moivre, 1967/1718, p. 1): "if we constitute a fraction whose numerator is the number of times the event could occur and the denominator is the number of times the event could occur or fail to occur, this fraction would be a true definition of the probability of occurrence". This definition is subsequently reformulated by Laplace, resulting in the Laplace Rule: "the probability of an event corresponds to the proportion of the number of favourable cases to the number of possible cases, as long as the results are equally probable" (Laplace, 1985/1814, p.28). Although this definition predominates in the school context as a result of its mathematical simplicity, in Laplace's time it was considered inappropriate since "in addition to being circular and restrictive, it did not answer the question of what exactly probability is and only provided a 
practical method for calculating probability in some simple events" (Godino, Batanero, \& Cañizares, 1987, p. 21). We should therefore exercise caution when applying this definition as it may generate the bias of equiprobability by not complying with the condition of equiprobability. Moreover, it cannot be applied in experiments with an infinite number of possibilities or when the sample space is finite but not symmetrical (Lecoutre, 1992).

Frequency approach: as a result of the controversies presented by the classical approach to probability, and of the new fields of application of probability, linking it to the study of income, insurance products, annuities, and mortality tables, among others, the frequency approach emerges to respond to the question of how to study data over time; i.e. to be able to analyse how data behaves in an experiment. From this perspective, in 1713 Bernoulli suggests the assignation of the probabilities of an event according to the relative frequency observed in a large number of repetitions of an experiment, which would enable an estimate of the probability of the event observed (Bernoulli, 1987/1713). As a result, probability is understood as "the point at which the frequencies of occurrences observed of a specific event converge when the series of experiments is increased (von Mises, 1952/1928). From this perspective, the main element is the objectivity of the concept of probability, beyond any consideration of personal factors which are subject to practical demonstration through experimentation. Although the frequency approach to probability brings objectivity, helps solve the difficulties presented by the classical approach, and also helps to widen the field of application by linking statistics with probability, it does present certain limitations in the classroom (Batanero et al., 2005). Among these limitations it is worth noting the impossibility of carrying out an experiment countless times under the same conditions to be able to determine the probability of an event occurring; the fact that it only provides approximate values and does not enable an exact value to be obtained; the exact number of tests needed for a good estimate is unknown; and, finally, it cannot be applied to events which, although random, are unrepeatable. Nevertheless, despite these difficulties, the approach presents potential for classroom application, such as, for example, the use of software to simulate a high number of random experiments.

Subjective approach: this is based on information related to the conditions, beliefs and knowledge held by the subject carrying out the measurement of probability concerning the truth of a certain proposition, and which is therefore not determined (de Finetti, 1937). From this approach, probability loses its objective nature and is understood as an indicator of degrees of personal belief in which probability is assigned to an event by a particular person, which can be significantly different from the subjective probability stipulated by another person; i.e. in this case, probability depends on the observer and on what this observer knows about the phenomenon or event being studied (Hacking, 1995). In other words, probability is interpreted as "the degree of belief or conviction regarding the occurrence of an affirmation. In this context, the probability represents a personal opinion about an unforeseeable phenomenon" (Canavos, 1988, p. 31). The contribution of this approach was a key element in the development of statistical inference, widening the scope of application of probability to areas such as medicine and to the study of economic decisions, to mention some. Furthermore, this approach is useful and interesting in the classroom as a teaching tool, since it allows the study of probability to be linked to students' previous experiences which, in the first instance (intuitive approach), enabled them to measure the possibility of an event occurring in a qualitative way, which now, adopting the subjective approach, allows them to measure the probability of an event occurring quantitatively, taking into account objective information on it (relative frequencies, reasons for equiprobability, etc.).

Axiomatic approach: in the 20th century, probability shifts from an objective approach (frequency view) to a subjective approach, insofar as it obtains the character of a formalised mathematical theory that can be used to describe and interpret the reality of random phenomena (Batanero, 2005). This is mainly thanks to Kolmogorov, who manages to connect probability with modern mathematics, establishing a satisfactory axiomatic for probability in 1937 on the basis of the theory of measurement and the theory of clusters, which is accepted by different schools, regardless of their philosophical interpretations of probability (Batanero \& Díaz, 2007). In line with Kolmogorov, events can be represented through clusters in which the sample space $(\Omega)$ would be the total cluster and the different events would correspond to subclusters of it. In this regard, probability is considered as a regulated measurement, delimited between 0 and 1 , and defined according to these clusters. Within this approach, it is possible to define a $\sigma$-algebra of events $\rho$ on this sample space, in which any $P$ function defined in relation to $\rho$ complies with the following three axioms of probability:

i. The probability of any event $\mathrm{A}$ in rho is either positive or zero, which is to say that $\mathrm{P}(\mathrm{A}) \geq 0$. To a certain extent, probability measures the difficulty of an A event occurring (the lower the probability, the more difficult it is for it to occur). 
Table 1. Distribution by class level of classes on probability video-recorded

\begin{tabular}{cccccccccc}
\hline School year & 1st of PE & 2nd of PE & 3rd of PE & 4th of PE & 5th of PE & 6th of PE & 7th of PE & 8th of PE \\
\hline $\begin{array}{c}\text { No. of classes } \\
\text { video-recorded }\end{array}$ & 1 & 1 & 1 & 3 & 4 & 6 & 4 & 3 \\
\hline
\end{tabular}

ii. The probability of the sample space Omega is 1 , which is to say that $P(\Omega)=1$. Therefore, probability is always greater than 0 and less than 1 (probability zero means that there is no possibility of it occurring (it is an impossible event), and probability 1 means that it always occurs (it is a certain event).

iii. The probability of the union of any cluster of incompatible events is the sum of probabilities of the events. That is, if $A_{1}, \ldots, A_{n}, \ldots$ is an infinite sequence of incompatible events, that is: $A_{i} \cap A_{j}=\emptyset, \forall i \neq j$ then: $P\left(\cup_{i=1}^{\infty} A_{i}\right)=\sum_{i=1}^{\infty} P\left(A_{i}\right)$.

In this way, any $\mathrm{P}$ function that satisfies Kolmogorov's three axioms is called a probability measurement or, simply, probability.

Over the years, the different approaches to probability described have helped to establish and develop the Theory of Probability which provides models for phenomena in which uncertainty is relevant. In this way, probability is currently considered to be one of the most fertile branches of mathematics (Godino et al. 1987). In this sense, it is important to adopt a perspective of probability modelling in which such debates and different approaches complement each other; since real understanding of the concept cannot be limited to one of said approaches (Batanero et al., 2005; Steinbring, 1990). It is therefore vital for teachers to have the probabilistic teaching knowledge that will help them guide the teaching process in a progressive way, starting with their students' intuitive ideas on chance and probability, before going on to incorporate the different approaches and to gradually construct the concept. As Laplace indicated: "learning probability helps us avoid false expectations when taking decisions, and therefore our study is absolutely relevant and useful and should be included in the mainstream education system" (Laplace, 1985/1825, p. 206-207).

\section{METHOD}

A qualitative approach has been adopted to design a descriptive case study, since the aim is to describe and understand teaching practice in relation to the teaching of probability (Bisquerra, 2009). The following phases were followed in order to obtain the data:

\section{Phase 1: video-recording of the class sessions}

The classes of 12 Chilean Primary Education teachers that covered statistics and probability were videorecorded over the course of one school year (63 sessions of the different levels, from grade 1 to 8 ). Teachers were selected on the basis of the following criteria: they delivered maths classes at one of the levels of Primary Education and had at least five years' experience; they were recognised and recommended by their peers and management teams for their good practices in maths teaching; they obtained good results in teacher measurement indices; they participated constantly in ongoing training in relation to maths and maths teaching; they had taught probability more than once in the last 3 years; their students achieved good results in mathematics in local and national tests (Rojas, Carrillo, \& Flores 2012).

The teacher wore an audio recorder around their neck and a video camera was also used to record the teacher and the whole group. The camera was located in a corner of the room, thus capturing the whiteboard and most of the students in the room. During filming, the person recording paid attention to what was happening in the room, moving the camera when necessary or zooming in to capture what was happening more effectively. The camera followed the teacher constantly (since he/she was the focus of the study), taking in as many students as possible and zooming in to record teacher-student interactions or to focus on the worksheets when a student or students were explaining something written on them.

\section{Phase 2: selection of the class sessions}

Of all the classes recorded (63), only those that covered topics related to the subject of chance or probability at the different levels of Primary Education (PE) were selected. In total, this amounted to 23 classes of between 45 and 90 minutes that made up the total units of analysis of this study (Table 1).

Sessions were selected with the aim of obtaining systematic information to enable us to examine the teaching of probability, thus identifying episodes of classes in which we observe the presence of elements that characterise the different approaches to probability. 
Table 2. Rubric for Observing Approaches to Probability (ROAP)

\begin{tabular}{|c|c|}
\hline $\begin{array}{l}\text { Approaches to } \\
\text { probability }\end{array}$ & Indicators \\
\hline $\begin{array}{l}\text { Intuitive } \\
\text { approach }\end{array}$ & $\begin{array}{l}\text { 1. Focus on daily life situations related to the use of stochastic terms and with an expression of the degree of } \\
\text { belief that the event will occur (through a qualitative scale). } \\
\text { 2. Use of common verbal terms and expressions related to probabilistic language which are used in both a } \\
\text { probabilistic and daily life context. } \\
\text { 3. Emphasis on the possibility of the occurrence as a qualitative scale that goes from the certain to the } \\
\text { impossible. } \\
\text { 4. Unpredictability and variability of events and their possible results. } \\
\text { 5. Exploration and distinction of random phenomena, differentiating them from deterministic phenomena. } \\
\text { 6. Distinction between types of events (certain, possible, unlikely, uncertain). } \\
\text { 7. Analysis of examples and intuitions related to chance and probability. }\end{array}$ \\
\hline & $\begin{array}{l}\text { 1. Focus on problem situations directed at calculating probabilities, determining the probability of theoretical } \\
\text { occurrence based on the data observed in a random experiment. } \\
\text { 2. Use of specific verbal terms and expressions of probability. } \\
\text { 3. Representation of probability of occurrence through a quantitative scale whose values fluctuate between } 0 \\
\text { and } 1 \text {. } \\
\text { 4. Emphasis on concepts and properties such as sample space, favourable and non-favourable cases, fair play, } \\
\text { probability of occurrence as measure of uncertainty, simple equiprobable events, and the Laplace Rule. } \\
\text { 5. Procedures focused on the construction of sample space, distinguishing between favourable and non- } \\
\text { favourable cases, comparing probabilities, assigning probabilities through the Laplace rule, constructing } \\
\text { diagrams for listing favourable cases. } \\
\text { 6. Analysis of examples, developing inductive reasoning. }\end{array}$ \\
\hline $\begin{array}{l}\text { Frequency } \\
\text { approach }\end{array}$ & $\begin{array}{l}\text { 1. Focus on carrying out predictions based on the data observed in a random experiment. } \\
\text { 2. Use of specific verbal terms and expressions of probability (population, estimated value, simulation, } \\
\text { theoretical and experimental probability, trends, frequencies, proportion, etc.). } \\
\text { 3. Use of graphic and tabular representations. } \\
\text { 4. Emphasis on the independence of events, stabilisation of frequencies and on the range of relative frequency } \\
\text { of an event (between } 0 \text { and } 1 \text { ). } \\
\text { 5. Procedures focused on making predictions based on the data observed, estimating probabilities on the basis } \\
\text { of repetitions of the same random experiment, recording results of a random experiment whether in tabular } \\
\text { or graphic form, interpreting, calculating and representing frequencies, interpreting tables and graphs, } \\
\text { simulating random experiments manually and/or using software. } \\
\text { 6. Analysis of examples and simulations of experiments whether manually or using software. }\end{array}$ \\
\hline $\begin{array}{l}\text { Subjective } \\
\text { approach }\end{array}$ & $\begin{array}{l}\text { 1. Focus on problem situations where the probability of occurrence can be affected (change) by the information } \\
\text { at hand (previous assignations are adjusted incorporating new information provided). } \\
\text { 2. Use of common verbal terms and expressions linked to probabilistic language. } \\
\text { 3. Emphasis on probability understood as degree of belief in events. } \\
\text { 4. Focus on uncertain events, uncertainty and the unpredictability of possible results, where probability is } \\
\text { determined by the information available. } \\
\text { 5. Procedures focused on analysing experiments, and where the probability of occurrence depends on the } \\
\text { information available, assessing the probability of occurrence of an event based on personal experience. } \\
\text { 6. Analysis of examples and previous experience that help to adjust prior assignations of probability based on } \\
\text { new information. }\end{array}$ \\
\hline $\begin{array}{l}\text { Axiomatic } \\
\text { approach }\end{array}$ & $\begin{array}{l}\text { 1. Focus on problem situations involving the axiomatics of probability to quantify the uncertainty of results in } \\
\text { random abstract experiments. } \\
\text { 2. Use of terms and expressions linked to the theory of compounds, the algebra of compounds and the theory of } \\
\text { measurement. } \\
\text { 3. Emphasis on probability as a measure of uncertainty. } \\
\text { 4. Procedures focused on the axiomatics of probability. } \\
\text { 5. Analysis and verification of properties linked to the axiomatics of probability. }\end{array}$ \\
\hline
\end{tabular}

\section{Phase 3. Transcription and coding of data}

During this phase the video-recorded classes were transcribed and coded. The Rubric for Observing Approaches to Probability (ROAP) (Vásquez \& Alsina, in press) was used to carry out the coding, which aims to identify episodes during class in which certain practices linked to approaches to probability are observed. The videos thus enabled us to detect the presence/absence of approaches to probability in the primary classroom. This instrument considers a set of indicators related to and underpinning approaches to probability and the elements that characterise them in relation to probability problems, procedures, language, properties and concepts (Batanero, 2005); the analysis of international and Chilean guidelines on the teaching of probability in Primary Education (Vásquez \& Alsina, 2014), and the analysis of the teaching of probability in Chilean Primary Education textbooks (Vásquez \& Alsina, 2015, 2017). This rubric was validated by 5 experts in the teaching of statistics and probability in Spain, Chile, Argentina and Mexico, in a process which helped to refine the indicators and to verify that they measure what they set out to measure. Table 2 shows the (ROAP), with the indicators used for coding. 
Table 3. Example of the coding process

\section{Contextualisation of class}

Rosario is a teacher of 2 nd grade of primary which includes 20 students of 7 and 8 years old. The objective of this class is to

introduce students to the use of the language of chance and probability so that they will be able to predict and make conjectures on the possibility of events occurring.

In class, the teacher presents a series of worksheets that talk about different situations that the students are familiar with and in which uncertainty appears. Students discuss the possibility of occurrence.

Teacher: What are we referring to when we say that something is impossible, possible, certain or uncertain?

Students: Something is impossible when there is no chance of it happening or when it is really unlikely for it to happen.

Teacher: Can you give me an example?

Students: Winning the lottery. My mum says it's impossible to win it.

Teacher: Diego (student), it's not that it's impossible to win the lottery, but rather that it's really difficult to win it. That's why we say that winning it is very unlikely.

Student: So it's just about luck then. I mean it can happen, but it doesn't happen that often.

In the process of construction and validation, the following conditions presented in the literature in relation to protocols for observing classes are considered: a) observable categories are differentiated according to those which are directly observable and those that require interpretation, and which therefore need to be inferred by the coders, since a questionnaire containing only elements of low inference would result in validity problems, even if the instrument is reliable; b) the indicators of the dimensions are codifiable in periods of time of between 5 and 7.5 minutes and indicators of the dimensions raised are used (Praetorius, Pauli, Reusser, Rakoczy, \& Klieme 2014). It is due to the latter point that each video-recording of a class was divided into segments of 7.5 minutes, dichotomising the corresponding indicators to the elements that characterise the approaches to probability, assigning scores to each indicator according to presence (1) or absence (0) in each one of the class segments.

Coding of the class videos was carried out by a ternary of external coders, specialised in Primary Education Maths Teaching, since "lessons should be observed by at least two evaluators" (Schlesinger \& Jentsch 2016, p. 36). It is important to point out that the coders were experts in either the Didactics of Probability, or in the coding of mathematics classes in general.

In order to guarantee the reliability of the codings, the ternaries underwent a calibration process in which they considered the coding sessions together and discussed their disagreements. This was followed by a process of individual coding, which enabled us to assess inter-peer reliability levels, achieving reliability coefficients above $80 \%$, which is above the acceptable minimum (Tinsley \& Brown 2000). Finally, the 23 videos were double coded in 2 rounds of 8 videos and a third round of 7 videos in which the same levels of coder calibration were maintained, resulting in agreement percentages above $80 \%$, as in the first stage of calibration. Table 3 shows an example of the coding process of a microsegment of segment 3 of the class.

In segment 3 of the class, lasting from minute 15 to minute 22.5 , we initially observe the presence of indicator 3 of the intuitive approach, since the emphasis is placed on the possibility of occurrence on a qualitative scale that goes from the certain to the impossible. Similarly, we observe the use of common verbal terms and expressions of probabilistic language which are used in both a probabilistic context and in daily life (indicator 2). As a result, in this microsegment, indicators 3 and 2 (respectively) of the intuitive approach have been coded with the value " 1 " to denote the presence of the indicator.

\section{RESULTS}

The results of this study are based on the analysis of the 23 video-recorded classes carried out by 12 primary school teachers. In line with our objectives, the results are presented in two sections: firstly, we present the approaches to probability that were carried out by the participants of the study, and secondly we analyse the teaching trajectories implemented in relation to these approaches.

\section{Approaches to Probability}

In the first instance, we have analysed the presence/absence of the indicators in all of the class segments, which is to say the elements that characterise each of the approaches to probability shown in Table 1. Figure 2 shows the differences related to the presence of the approaches to probability for each level of Primary Education, in which the area of each zone within the bars represents the relative percentage of the presence of the approaches to probability (intuitive, classical, frequency and subjective). 


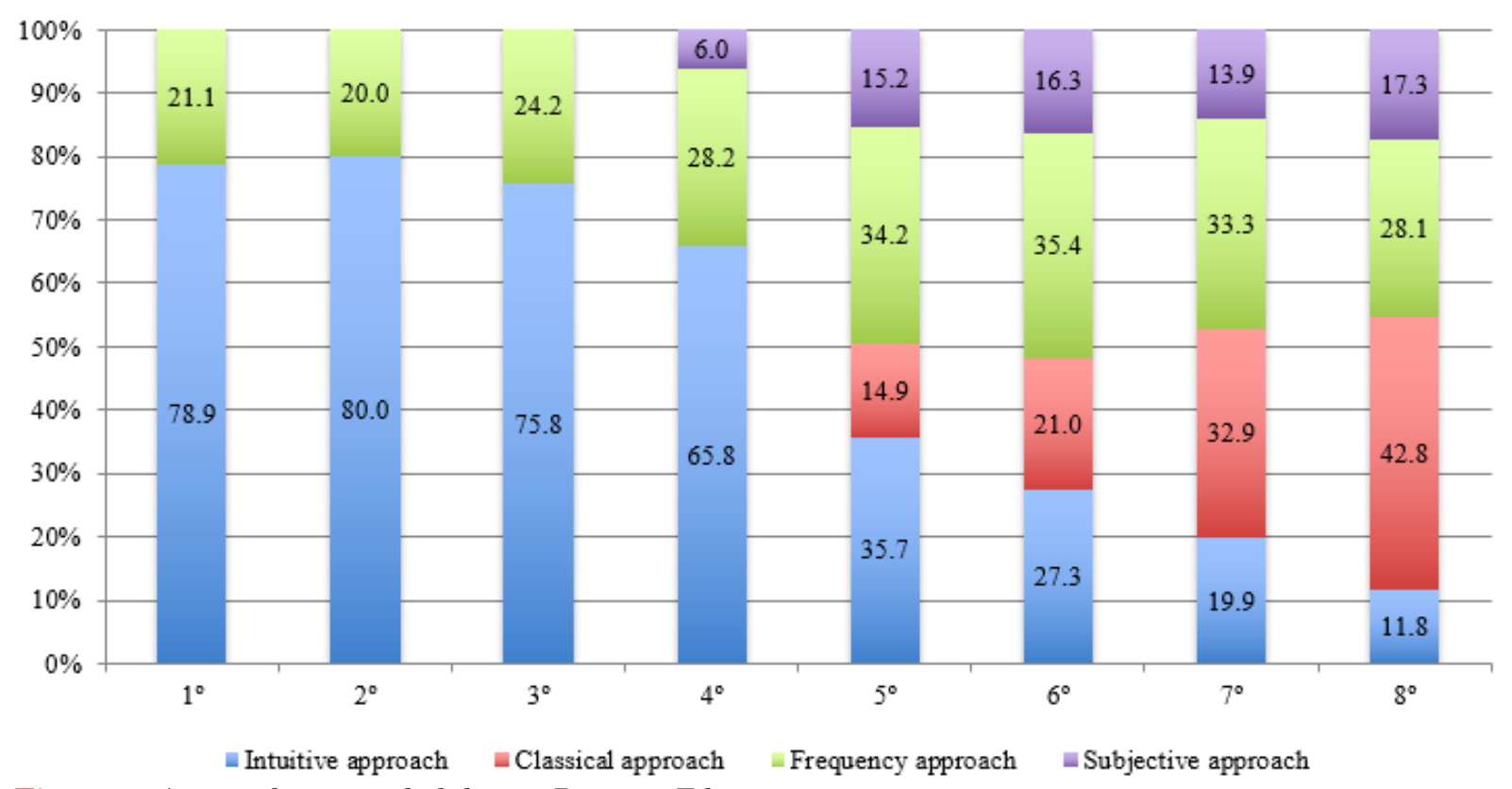

Figure 2. Approaches to probability in Primary Education

The results obtained show a strong presence of intuitive approaches (above $75 \%$ ) at initial levels (1st - 3rd grade), in conjunction with a much lower presence of frequency approaches and the absence of other approaches.

As the level increases, the presence of the intuitive approach decreases (below $12 \%$ in the final grade), being replaced by frequency, subjective and classical approaches. We therefore find that frequency and classical approaches become particularly dominant in the final levels, with the latter reaching a predominance of $42.8 \%$ in grade 8 . We can also observe that of the five indicators of the ROAP for the axiomatic approach, none are present in the video-recorded classes.

\section{Teaching Trajectories of the Approaches to Probability}

To present the results related to the teaching trajectories of the approaches to probability, we focus our analysis on the indicators with greater or lesser presence, since they help show the trends at each level. Below we show the results for each of the approaches, presenting the distribution of the presence of the indicators defined and validated for this study with graphs, where the height of the bars represents the relative percentage of each indicator for each level (1st to 8th grade of Primary Education).

\section{Intuitive approach}

Regarding the indicators that characterise the intuitive approach to probability, Figure 3 shows that none are situated below $25 \%$, except indicators 3, 4 and 7 at 8 th grade, which shows that at these levels participants in our study give little attention to possibility as a qualitative scale that goes from the certain to the impossible, the unforeseeable and the variability of events and their possible results, and also to the analysis of examples and intuitions linked to chance and probability. This is related to the decrease of this approach in the final years of Primary Education, where classical and frequency approaches acquire more relevance, as indicated above. Furthermore, most indicators (above 75\%) are situated at initial levels, clearly showing that it is at these levels when this approach is worked on most consistently. To be more precise, at the initial level, six of the seven indicators are situated above $75 \%$ (exploration and distinction of random phenomena, differentiating them from deterministic phenomena is the only indicator that does not exceed this figure, although it stands at a reasonable 60\%); at the second level we find three indicators with a very significant presence: the use of common verbal terms and expressions related to probabilistic language used in both probabilistic and daily life contexts; the emphasis on the possibility of occurrence as a qualitative scale that goes from the certain to the impossible; and the unpredictability and variability of events and their possible results. At grade three, four, six and seven, considerable importance continues to be given to the use of common verbal terms and expressions related to probabilistic language used in both a probabilistic and daily life context. At grade four, 


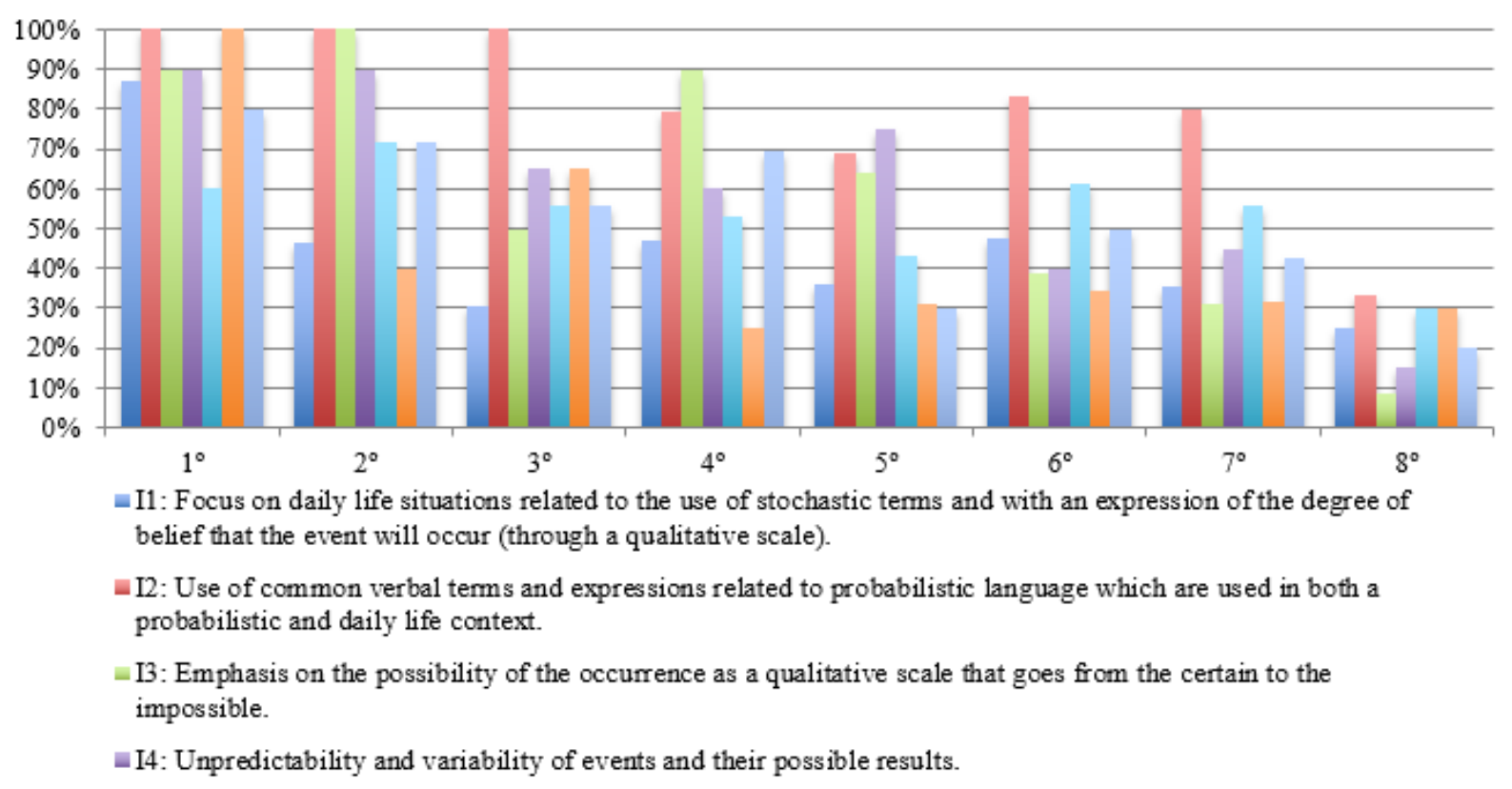

I5: Exploration and distinction of random phenomena, differentiating them from deterministic phenomena.

I6: Distinction between types of events (certain, possible, unlikely, uncertain).

I7: Analysis of examples and intuitions related to chance and probability.

Figure 3. Presence of elements that characterise the intuitive approach to probability in Primary Education

the emphasis on the possibility of occurrence as a qualitative scale going from the certain to the impossible is also situated above $75 \%$ and, finally, unpredictability and the variability of events and their possible results also stands at $75 \%$ at grade five. The other indicators are above $25 \%$ and below $75 \%$ at all levels, thus showing that aspects such as the exploration and distinction of random phenomena, differentiating them from deterministic phenomena, are not worked on with the same frequency, but are nevertheless worked on in some way.

It can also be seen that, with regard to the participants in our study, all the indicators defined to characterise the intuitive approach to probability are present throughout all levels of Primary Education, thus highlighting the importance of working on this approach in a gradual way, since it provides the scaffolding to then construct the concept of probability progressively on the basis of the students' intuitive ideas on chance and probability.

\section{Classical approach}

The results obtained for the six indicators underpinning the classical approach to probability, highlighted in Figure 4, show that these are all absent in the first four grades of Primary Education, thus revealing that it is in the last years of this educational stage when the teachers participating in our study introduce this approach.

As we can observe from the data presented in Figure 4, it is at grade five that teachers start to introduce the classical approach to probability in a gradual way, with particular emphasis on the introduction of concepts and properties such as: sample space, favourable and non-favourable cases, equiprobability, the Laplace rule, etc., reaching a presence above $75 \%$ at this level, followed by the use of specific terms and verbal expressions of probability (43\%). We also observe a fairly low level (below 25\%) of the representation of probabilities of occurrence on a quantitative scale and of procedures focused, for example, on the construction of the sample space of a random experiment. It is noteworthy that the emphasis on concepts and properties drops at grade six, meaning that the other indicators acquire certain relevance, with a presence rate that oscillates between $27 \%$ and $52 \%$, which - with the exception of indicator four - denotes a progressive increase up to levels 7 and 8 , when they reach a percentage presence above $60 \%$ for all the indicators, thus showing the strong dominance 


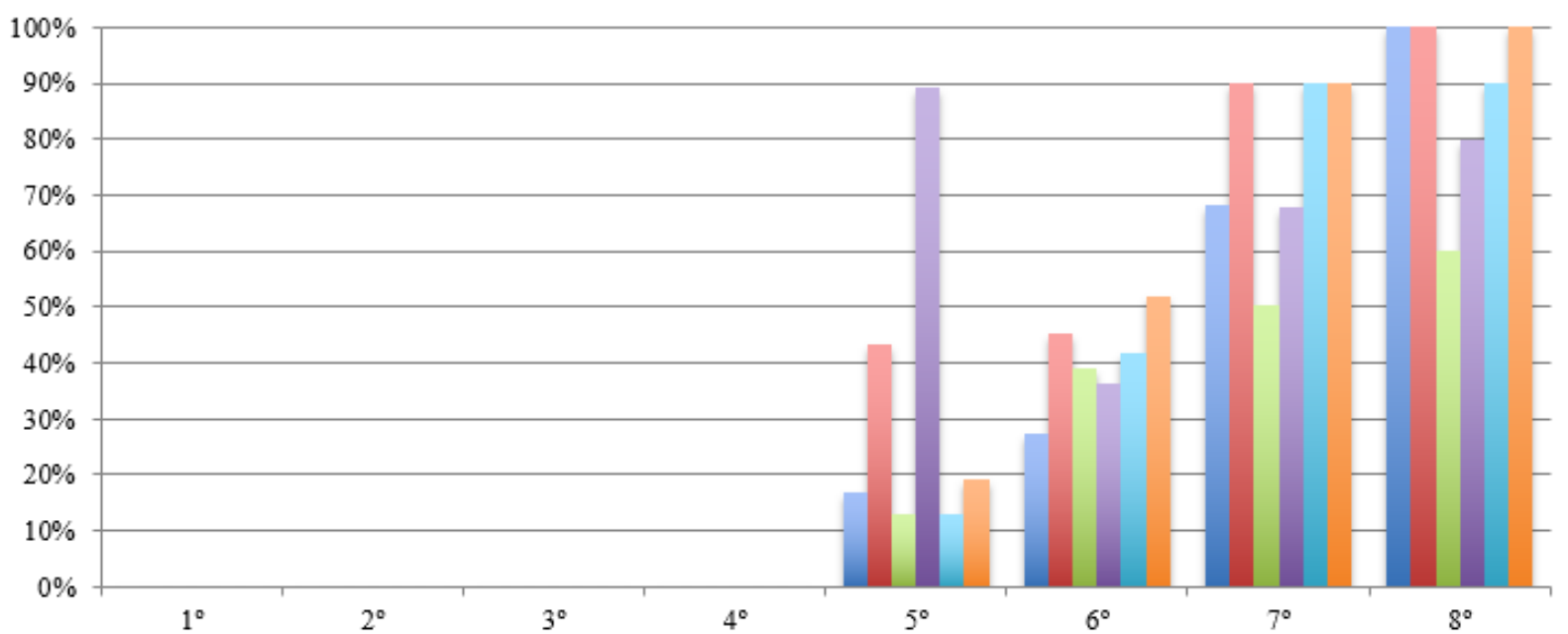

I1: Fœcus on problem situations directed at calculating probabilities, determining the probability of theoretical occurrence based on the data observed in a random experiment.

$=\mathrm{I} 2$ : Use of specific verbal terms and expressions of probability.

I3: Representation of probability of occurrence through a quantitative scale whose values fluctuate between 0 and 1 .

I4: Emphasis on concepts and properties such as sample space, favourable and non-favourable cases, fair play, probability of occurrence as measure of uncertainty, simple equiprobable events, and the Laplace Rule.

\begin{abstract}
I5: Procedures focused on the construction of sample space, distinguishing between favourable and non-favourable cases, comparing probabilities, assigning probabilities through the Laplace rule, constructing diagrams for listing favourable cases.
\end{abstract}

I6: Analysis of examples, developing inductive reas oning.

Figure 4. Presence of elements that characterise the classical approach to probability in Primary Education

of the elements that characterise this approach in the teaching practice of the upper years of Primary Education, above all with regard to the use of specific verbal terms and expressions of probability.

\title{
Frequency approach
}

In general terms, and in the same way as the intuitive approach, Figure 5 shows that all the indicators underpinning this approach are present in the teaching practice of the participants of our study and are progressively introduced at all levels of Primary Education. We also see that indicator two is presented with most frequency in grades three, seven and eight, showing the importance that teachers of these levels give to the use of specific verbal terms and expressions of probability (e.g. population, estimated value, theoretical and experimental simulation of probability, trend, frequencies, proportion, etc.) when teaching probability. In addition, the data reflects a low usage of graphic and tabular representations linked to the teaching of probability from a frequency approach, except in grade seven, as well as a tenuous presence of teaching practices linked to the establishment of frequencies in random experiments and the independence of events, below $40 \%$ in grades one to four and also in grade eight.

More specifically, the data obtained shows that in the initial years (grade 1 to 4 ), the predominance of this approach is strongly marked by the use of specific verbal terms and expressions of probability such as "population", "frequencies", "estimated value", followed by the use of graphic and tabular representations, while in the upper levels predominance is found in the use of verbal expressions and the carrying out of predictions based on the data observed in random experiments. Another important finding is that from level six the frequency approach acquires greater prominence (higher than 50\%), showing a decrease in the last year, when we see a rise in elements characteristic of the classical approach. 


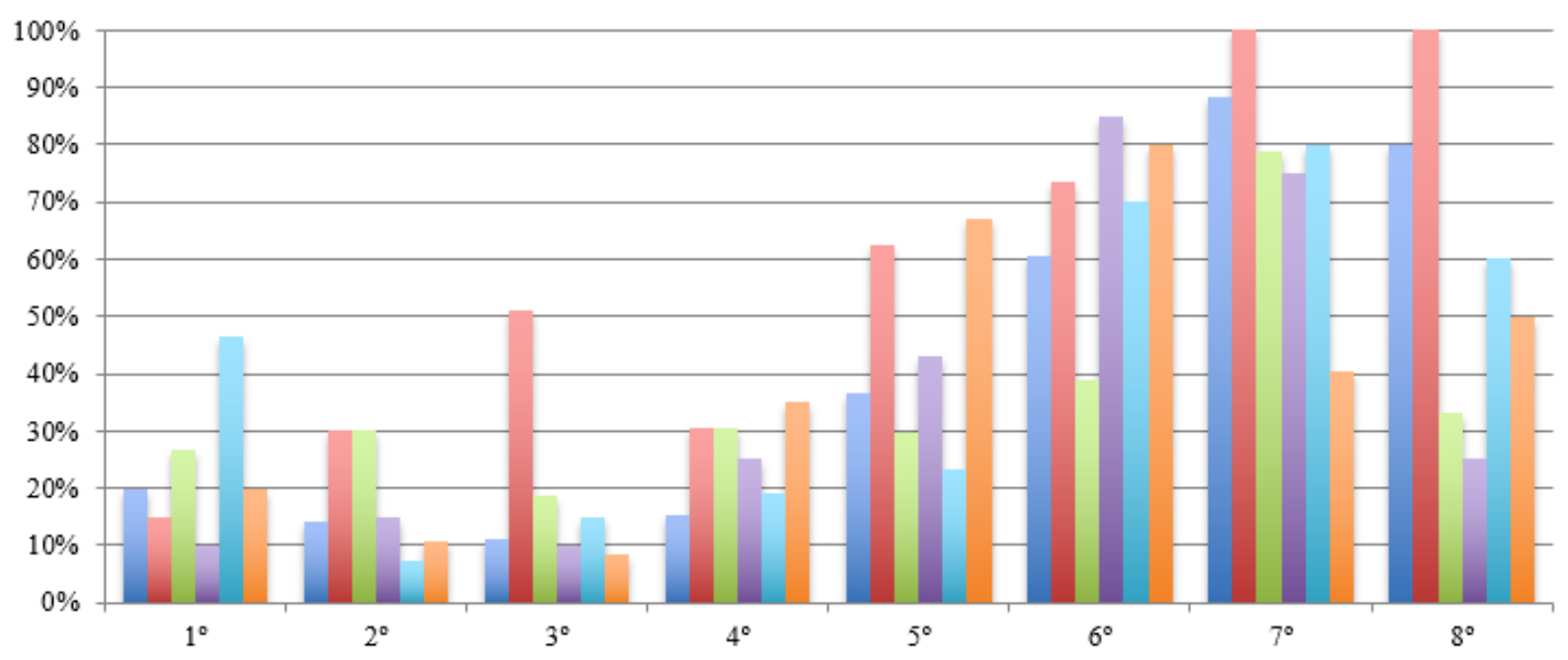

=I1: Focus on carrying out predictions based on the data observed in a random experiment. $=$ I2: Use of specific verbal terms and expressions of probability (population, estimated value, simulation, theoretical and
experimental probability, trends, frequencies, proportion, etc.).

- I3: Use of graphic and tabular representations.

\begin{abstract}
I4: Emphasis on the independence of events, stabilisation of frequencies and on the range of relative frequency of an event (betwee 0 and 1 ).

I5: Procedures focused on making predictions based on the data observed, estimating probabilities on the basis of repetitions of the same random experiment, recording results of a random experiment whether in tabular or graphic form, interpreting, calcula
\end{abstract}

I6: Analysis of examples and simulations of experiments whether manually or using software.

Figure 5. Presence of elements that characterise the frequency approach to probability in Primary Education

\title{
Subjective approach
}

In the first place, the results shown in Figure 6 enable us to see that nuances start to were carried out by the participants of the relation to this approach from the fourth grade of Primary Education, especially linking the use of verbal expressions to the analysis of previous experiences that enable an adjustment of previous assignations of probability on the basis of new information; procedures focused on analysing experiments in which the probability of occurrence depends on the information available; assessing the probability of occurrence of an event based on personal experiences and, finally, in the presence of situations and problems in which the probability of occurrence can be affected (change) according to the information available, leading to adjustments in assignations.

In the teaching practices of the upper grades of the participants in our study, we find a marked predominance of problem situations whose focus is on adjusting the previous assignations of probability, incorporating the new information available, as well as the predominance of the use of verbal expressions associated with probabilistic language. 


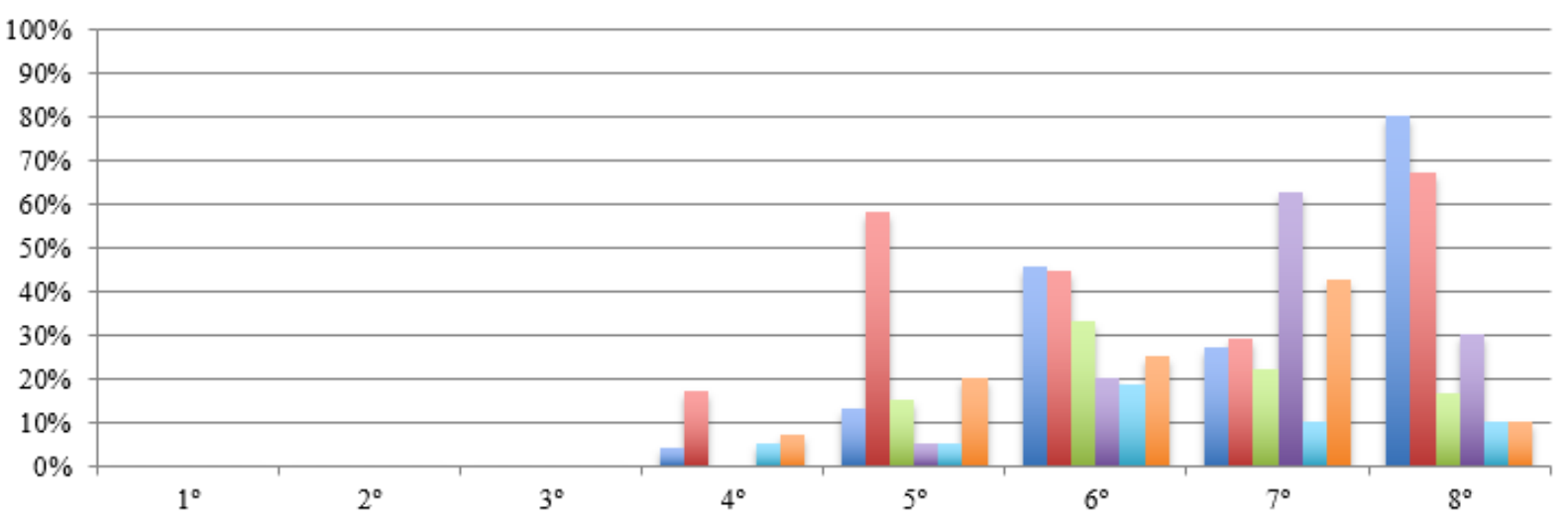

I1: Focus on problem situations where the probability of occurrence can be affected (change) by the information at hand (previous assignations are adjusted incorporating new information provided).

I2: Use of common verbal terms and expres sions linked to probabilistic language.

I3: Emphasis on probability understood as degree of belief in events.

I4: Focus on uncertain events, uncertainty and the unpredictability of possible results, where probability is determined by the information available.

I5: Procedures focused on analysing experiments, and where the probability of occurrence depends on the information available, assessing the probability of occurrence of an event based on pers onal experience.

I6: Analysis of examples and previous experience that help to adjust prior assignations of probability based on new information.

Figure 6. Presence of elements that characterise the subjectivist approach to probability in Primary Education

\section{CONCLUSIONS AND IMPLICATIONS FOR TEACHING}

The results obtained have provided evidence of the presence and absence of approaches to probability in the teaching practices analysed, as well as the teaching trajectories carried out. This has enabled us to draw some initial conclusions regarding the questions advanced in our study on what kind of probability is taught in Primary Education and how it is taught.

Regarding the teaching of probability, the teachers that comprise our unit of analysis focus their teaching practice mainly on intuitions related to chance and probability, as well as on probabilistic language. This data, which is in line with the curricular guidelines of the NCTM (2000), show that the language associated with daily life constitutes a key element, above all in the early stages of education, in order to go on to incorporate probabilistic language gradually, and to thus advance towards the construction of knowledge of probability. In our study, this trend is clearly reflected in the predominance presented by the indicators that refer to the probabilistic language associated with each approach, with these being, on average, the ones that present the highest percentages of presence for intuitive, classical, frequency and subjective approaches. To a large extent, this coincides with the historical-epistemological evolution of the concept (Batanero, 2005), enabling students to construct their conception of probability on the basis of their intuitive ideas based on experiences and contexts related to chance and probability.

Regarding the teaching trajectories of probability, the results obtained with the participants of our study show that the elements that characterise intuitive and frequency approaches are incorporated throughout the whole educational stage, with an average presence of $49.4 \%$ and $28.1 \%$ respectively. The subjective approach has an average presence of $8.6 \%$ and is introduced from grade four, while the elements related to the classical approach have an average presence of $13.9 \%$ and start to be introduced from grade five. It is important to point out that none of the indicators defined in the ROAP for the axiomatic approach to probability are present in Primary Education.

A more thorough analysis of the different approaches shows that the intuitive approach is present at all levels, with a marked presence in the initial levels, which decreases as the level increases, giving way to new 
elements that characterise the other approaches. The indicators with most presence are those related to the use of terms and common verbal expressions linked to the probabilistic language of probabilistic and daily life contexts (80.6\%) and the emphasis on the possibility of occurrence as a qualitative scale (59\%).

The intuitive approach is followed by the frequency approach, with a fairly lower average presence in which the elements that stand out for their presence relate to the use of terms and expressions such as estimated value, simulation, frequencies, proportion, etc. (27\%); and those related to making predictions based on the data observed in random experiments (21\%).

On the other hand, the classical and subjective approaches are only observed in the last years of primary and with considerably lower presence in relation to the other approaches, as already indicated. The elements that characterise the classical approach with the most presence are those related to the use of specific verbal terms and expressions of probability (35\%); the emphasis on concepts and properties such as sample space, fair play, the Laplace rule, probability as a measure of uncertainty, etc. (34\%), and finally, the analysis of examples for the development of inductive reasoning (33\%).

Finally, for the subjective approach, the element that stands out for its presence is the use of verbal terms and expressions related to this approach (27\%). Conditional probability and Bayes' theorem are not presented or analysed in Primary Education. Nevertheless, focus is placed on the analysis of problem situations where the probability of occurrence can be affected by the information available, leading to adjustments (change) in previous assignations, incorporating the new information available.

Based on the results obtained in this study, and with a view to professional development, we consider that while the curricular guidelines of different countries recommend initiating students in probability based on a frequency approach centred on experimentation and simulation (e.g. CCSSI, 2010; MEC, 2007), we think it is important to start teaching probability on the basis of students' probabilistic intuitions, especially during the first years of Primary Education. In view of this, it is recommended that classroom practice enables students to gradually construct mathematics knowledge related to probability on the basis of their probabilistic intuitions, until they obtain an overall view of probability taking into account its multiplicity of interpretations (Batanero, Henry, \& Parzysz, 2005). In this sense, the teaching of probability throughout Primary Education should not be limited exclusively to one of its interpretations. Instead, it should be taught in a comprehensive way, taking into account the multiplicity of interpretations and starting, as argued above, from probabilistic intuitions based on contextualised daily life situations before going on to include elements of the subjective approach, linking the study of probability to students' prior experiences in such a way that they can observe that the knowledge they have about an event can affect and modify the assignation of probability of occurrence (Godino, Batanero, \& Cañizares, 1987). From this perspective, students' probabilistic intuitions should be literacised, linking intuitive and subjective approaches. While the subjective approach in Primary Education does not contemplate the study of Bayes' theorem, for example, it can focus on aspects more appropriate to this educational level, such as the analysis of situations in which the possibility of occurrence varies depending on the information available. Subsequently, it is necessary to move towards the frequency approach, particularly through experimentation and simulation, supported by the use of technological resources which can be of great help in simulating large numbers of random experiments and thus gaining a better appreciation of the convergence of the results obtained (stabilisation of relative frequencies). Nonetheless, care needs to be taken when working with the frequency approach and it is important to be clear that while this approach may bring objectivity to the study of probability, it does not provide an exact value but rather approximations; the exact number of tests needed for a good estimate is unknown; and, finally, it cannot be applied to events that, although random, are unrepeatable. The study of probability in Primary Education should be completed by applying the classical approach through classroom practices that include intuitive, subjective and frequency approaches, as well as the different elements that characterise these approaches. Finally, in relation to the axiomatic approach, the results of our study and the arguments presented by Batanero (2005) indicate that this should be reserved for Secondary Education as a result of its complexity.

Further studies should be carried out with larger samples in order to establish more precisely the levels at which each approach should be introduced, as well as the most appropriate teaching strategies and resources for teaching probability. This will provide a valuable contribution to the professional development of Primary Education teachers and help to ensure more effective teaching of probability at this educational stage. 


\section{ACKNOWLEDGEMENTS}

This work was supported by the National Commission of Scientific and Technological Research of Chile under Grant FONDECYT N 11150412.

\section{Disclosure statement}

No potential conflict of interest was reported by the authors.

\section{Notes on contributors}

Claudia Vásquez - Pontificia Universidad Católica de Chile, Chile.

Ángel Alsina - Universidad de Girona, Spain.

\section{REFERENCES}

Alsubaie, M. A. (2015). Hidden curriculum as one of current issue of curriculum. Journal of Education and Practice, 6(33), 125-128.

Batanero, C. (2005). Significados de la probabilidad en la educación secundaria. RELIME, 8(3), 247-264.

Batanero, C., \& Díaz, C. (2007). Meaning and understanding of mathematics. The case of probability. In J. P. Van Bendegen and K. François (Eds.), Philosophical dimensions in mathematics education (pp. 107127). New York: Springer. https://doi.org/10.1007/978-0-387-71575-9_6

Batanero, C., Henry, M., \& Parzysz, B. (2005). The nature of chance and probability. In G. Jones (Ed.), Exploring probability in school: Challenges for teaching and learning (pp. 15-37). New York: Springer. https://doi.org/10.1007/0-387-24530-8_2

Bernoulli, J. (1987). Ars conjectandi- 4ème partie (N. Meunier, Trans.) Rouen: IREM.

Bisquerra, R. (2009). Metodología de la investigación educativa. Madrid: La Muralla.

Common Core State Standards Initiative. (2010). Common Core State Standards for Mathematics. Retrieved from http://www.corestandards.org/assets/CCSSI_Math\%20Standards.pdf

de Finetti, B. (1937). La prevision: ses lois logiques, ses sources subjectives. Annales de l'Institut Henri Poincaré, 7, 1-68.

de Moivre A. (1967). The doctrine of chances. New York: Chelsea Publishing.

Everitt, B. S. (2008). Chance rules: An informal guide to probability, risk, and statistics. New York: Copernicus, Springer-Verlag. https://doi.org/10.1007/978-0-387-77415-2

Fischbein. (1975). The intuitive sources of probabilistic thinking in children. Dordrecht: Reidel. https://doi.org/10.1007/978-94-010-1858-6

Gal, I. (2005). Towards "probability literacy" for all citizens: building blocks and instructional dilemas. In G. Jones (Ed.), Exploring Probability in Schools: Challenges for Teaching and Learning (pp. 39-63). New York: Springer. https://doi.org/10.1007/0-387-24530-8_3

Godino, J. D., Batanero, C., \& Cañizares, M. J. (1987). Azar y Probabilidad. Fundamentos didácticos y propuestas curriculares. Madrid: Síntesis.

Hacking, I. (1995). El surgimiento de la probabilidad: un estudio filosófico de las ideas tempranas acerca de la probabilidad, la inducción y la inferencia estadistica. Barcelona: Gedisa.

Laplace, P. S. (1985). Ensayo filosófico sobre las probabilidades. Madrid: Alianza Editorial.

Lecoutre, M. P. (1992). Cognitive Models and Problem spaces in "Purely Random" Situations. Educational Studies in Mathematics, 23, 557-568. https://doi.org/10.1007/BF00540060

Ministerio de Educación de Chile [MINEDUC]. (2012). Bases Curriculares 2012: Educación Básica Matemática. Santiago de Chile: Unidad de Curriculum y Evaluación.

Ministerio de Educación y Ciencia [MEC]. (2007). Boletín oficial del Estado. ORDEN ECI/2211/2007, del 20 de julio, por la que se establece el currículo y regula la ordenación de la Educación Primaria. Madrid, Spain.

Ministry of Education Singapore. (2007). Curriculum Planning and Development Division. Ministry of Education, Singapore. Retrieved from http://www.moe.gov.sg 
National Council of Teachers of Mathematics [NCTM]. (2000). Principles and standards for school mathematics. Reston, Va.: The National Council of Teachers of Mathematics.

National Curriculum. (1999). The National Curriculum for England, Mathematics. Retrieved from www.nc.uk.net

Orón J. V., \& Blasco, M. (2018). Revealing the hidden curriculum in Higher education. Studies in Philosophy and Education, 37(5), 481-498. https://doi.org./10.1007/s11217-018-9608-5

Praetorius, A.-K., Pauli, C., Reusser, K., Rakoczy, K., \& Klieme, E. (2014). One lesson is all you need? Stability of instructional quality across lessons. Learning and Instruction, 31(1), 2-12. https://doi.org/10.1016/j.learninstruc.2013.12.002

Rojas, N., Carrillo, J., \& Flores, P. (2012). Características para identificar a profesores de matemáticas expertos. In A. Estepa, A. Contreras, J. Deulofeu, M. C. Penalva, F. J. García and L. Ordoñez (Eds.), Investigación en Educación Matemática XVI (pp. 479-485). Jaén: SEIEM.

Schlesinger, L., \& Jentsch, A. (2016). Theoretical and methodological challenges in measuring instructional quality in mathematics education using classroom observations. ZDM: The International Journal on Mathematics Education, 48(1-2), 29-40. https://oi.org/10.1007/s11858-016-0765-0

Shaughnessy, J. M. (1992). Research in probability and statistics: Reflections and directions. In D. A. Grows (Ed.), Handbook of research on mathematics teachingand learning (pp. 465-494). New York: MacMillan.

Steinbring, H. (1990). The nature of stochastical knowledge and the traditional mathematics curriculum. Some experiences with in-service training and developing materials. En A. Hawkins (Ed.), Training teachers to teach statistics (pp. 2-19). Voorburg: ISI.

Tinsley, H. E. A., \& Brown, S. D. (2000). Handbook of Applied Multivariate Statistics and Mathematical Modeling. Gainesville, USA: Academic Press. https://doi.org/10.1016/B978-012691360-6/50002-1

Vásquez, C., \& Alsina, A. (2014). Enseñanza de la probabilidad en Educación Primaria. Un desafío para la formación inicial y continua del professorado. Números, 85, 5-23.

Vásquez, C., \& Alsina, Á. (2015). Un modelo para el análisis de objetos matemáticos en libros de texto chilenos: situaciones problemáticas, lenguaje y conceptos sobre probabilidad. Profesorado, Revista de currículum y formación del profesorado, 19(2), 441-462.

Vásquez, C., \& Alsina, Á. (2017). Aproximación al conocimiento común del contenido para enseñar probabilidad desde el modelo del Conocimiento Didáctico-matemático. Educación Matemática, 29(3), 79-108.

Vásquez, C., \& Alsina, Á. (in press). Diseño, construcción y validación de una pauta de observación de los significados de la probabilidad en el aula de Educación Primaria. REVEMAT.

von Mises, R. (1952). Probabilidad, estadística y verdad. Madrid: Espasa Calpe. 